\title{
COMMUNICATION
}

\section{PHOTOREDOX REACTION OF TRIAZIDOMERCURATE(II). GENERATION OF STABLE MERCURY ATOMS UNDER AMBIENT CONDITIONS}

\section{HORST KUNKELY and ARND VOGLER $\dagger$}

Institut für Anorganische Chemie, Universität Regensburg, Universitätsstraße 31, D-8400 Regensburg, F.R.G.

(Received 19 July 1989 ; accepted 23 August 1989)

\begin{abstract}
Upon ligand-to-metal charge-transfer excitation the complex $\left[\mathrm{Hg}\left(\mathrm{N}_{3}\right)_{3}\right]^{-}$in ethanol underwent a photoredox reaction $\left(\lambda_{\text {irr }}=254 \mathrm{~nm} ; \phi=0.02\right):\left[\mathrm{Hg}^{\mathrm{II}}\left(\mathrm{N}_{3}\right)_{3}\right]^{-} \rightarrow$ $\mathrm{Hg}^{0}+3 \mathrm{~N}_{2}+\mathrm{N}_{3}^{-}$. Elemental mercury was released in the form of metal atoms which are stable under ambient conditions.
\end{abstract}

Upon ligand-to-metal charge-transfer (LMCT) excitation many transition metal azide complexes undergo a redox reaction which leads to the formation of the free metal as a colloid. ${ }^{1}$ It is assumed that first free metal atoms are formed which agglomerate to smaller clusters, then to large clusters, and finally to colloidal particles. However, the metal atoms and clusters have not been detected since the agglomeration is apparently very rapid and does not stop at intermediate stages. In the present communication we report the direct observation of mercury atoms which are generated by the photolysis of $\left[\mathrm{Hg}\left(\mathrm{N}_{3}\right)_{3}\right]^{-}$in ethanol under ambient conditions. This observation is facilitated by the relatively high stability of mercury atoms. Our study is also an interesting contribution to the photochemistry of mercury(II) complexes. While several organometallic mercury(II) compounds ${ }^{2-5}$ are known to undergo a light-induced reductive elimination with the release of metallic mercury, the photochemistry of classical mercury(II) complexes seems to be rather complicated. ${ }^{3,6}$ Finally, our observations may be also important with regard to the mechanism of the mercury-photosensitized dehydrodimerization of organic compounds in solution ${ }^{7,8}$ and in the gas phase.

The absorption spectrum of $\left[\mathrm{Hg}\left(\mathrm{N}_{3}\right)_{3}\right]^{-}$(Fig. 1)

$\dagger$ Author to whom correspondence should be addressed. displays an intense band at $\lambda_{\max }=246 \mathrm{~nm}$ $(\varepsilon=5600)$. This band has not been detected before since it was obscured by the absorption spectrum of $\left[\mathrm{As}\left(\mathrm{C}_{6} \mathrm{H}_{5}\right)_{4}\right]^{+}$, which was used as counter-ion for the isolation of the complex anion. ${ }^{9}$ Upon irradiation of $\left[\mathrm{Hg}\left(\mathrm{N}_{3}\right)_{3}\right]^{-}$in ethanol with white or monochromatic light $\left(\lambda_{\text {irr }}=254 \mathrm{~nm}\right)$ nitrogen was evolved which was detected by gas chromatography. Free azide was also formed. It was identified as the red $\mathrm{Fe}^{3+}$ complex. Simultaneously the absorption band of $\left[\mathrm{Hg}\left(\mathrm{N}_{3}\right)_{3}\right]^{-}$disappeared (Fig.

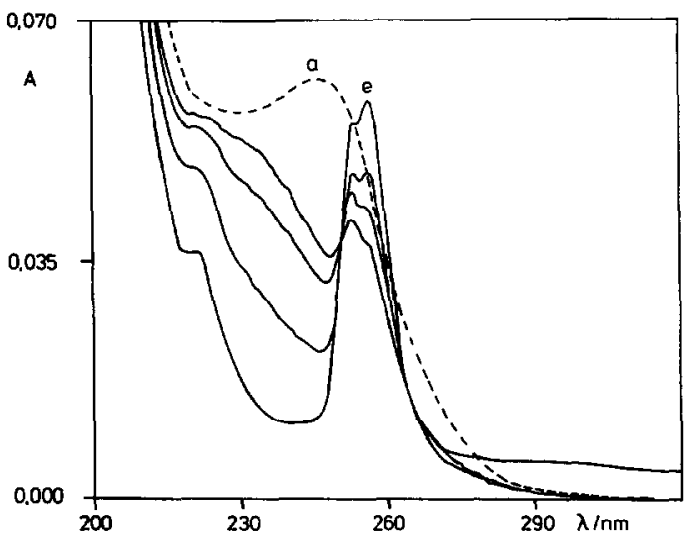

Fig. 1. Spectral changes during the photolysis of $1.04 \times 10^{-5} \mathrm{M}\left[\mathrm{N}\left(\mathrm{C}_{4} \mathrm{H}_{9}\right)_{4}\right]\left[\mathrm{Hg}\left(\mathrm{N}_{3}\right)_{3}\right]$ in $\mathrm{C}_{2} \mathrm{H}_{5} \mathrm{OH}$ at (a) 0 , $3,6,12$ and (e) 18 min irradiation time, with white light irradiation (Osram HBO $100 \mathrm{~W} / 2$ lamp) and a 1-cm cell. 
1). The spectral changes which accompanied the photolysis are characterized by the appearance of a new narrow band with two maxima at $\lambda=253$ and $256 \mathrm{~nm}$. This absorption ${ }^{8,10-12}$ indicated the formation of atomic mercury. Since the solubility of elemental mercury is rather low in all common solvents $\left(\sim 10^{-7} \mathrm{M}\right),{ }^{12}$ the photochemical generation of the free metal did not only lead to the appearance of mercury atoms. The bulk metal was also formed. At later stages of the photolysis the release of colloidal metal can be recognized by an increase of the extinction coefficient over the entire absorption spectrum. This effect is apparently caused by light scattering of colloidal metal particles. ${ }^{\prime}$

The photolysis of $\left[\mathrm{Hg}\left(\mathrm{N}_{3}\right)_{3}\right]^{-}$was monitored by measuring the decrease of the extinction coefficient at $246 \mathrm{~nm}$, taking into account a residual absorption of the photolysis product of about $20 \%$ at this wavelength. The absorbed light intensity $\left(1.4 \times 10^{-10} \mathrm{E} \mathrm{s}^{-1}\right)$ was determined with a Polytec pyroelectric radiometer, calibrated and equipped with a RkP-345 detector. For quantum yield determinations the amount of photolysis was limited to less than $10 \%$. At an irradiating wavelength of $\lambda=254 \mathrm{~nm}$ the quantum yield for the disappearance of $\left[\mathrm{Hg}\left(\mathrm{N}_{3}\right)_{3}\right]^{-}$was $\phi=0.02$.

The absorption band of $\left[\mathrm{Hg}\left(\mathrm{N}_{3}\right)_{3}\right]^{-}$(Fig. 1) at $\lambda_{\max }=246 \mathrm{~nm}$ is assigned to a LMCT transition involving the promotion of an electron from the reducing azide ligands to the empty $6 s$ orbital of mercury(II). Analogous LMCT assignments were made for the mercury(II) halides, $\mathrm{HgX}_{2},{ }^{13-15}$ and halide complex anions, $\left[\mathrm{HgX}_{4}\right]^{2-},{ }^{15-17}$ with $\mathrm{X}=\mathrm{Cl}$, $\mathrm{Br}$ and I. Since $\mathrm{Br}^{-}$and $\mathrm{N}_{3}^{-}$have the same optical electronegativities $(2.8)^{19}$ the LMCT bands of $\left[\mathrm{HgBr}_{4}\right]^{2-}\left(\lambda_{\max }=253 \mathrm{~nm}\right)^{16,17}$ and $\left[\mathrm{Hg}\left(\mathrm{N}_{3}\right)_{3}\right]^{-}$ appear at comparable energies.

Upon LMCT excitation $\left[\mathrm{Hg}\left(\mathrm{N}_{3}\right)_{3}\right]^{-}$undergoes a photoredox reaction according to the equation:

$$
\left[\mathrm{Hg}^{\mathrm{II}}\left(\mathrm{N}_{3}\right)_{3}\right]^{-} \rightarrow \mathrm{Hg}^{0}+3 \mathrm{~N}_{2}+\mathrm{N}_{3}^{-} \text {. }
$$

The formation of metallic mercury is not surprising since organometallic mercury(II) complexes are well known to show this photoredox behaviour. ${ }^{2-5}$ In some cases it has been demonstrated that this is initiated by $\mathrm{CT}$ excitation. ${ }^{4,5}$ The most interesting aspect of the present work is the observation of stable mercury atoms which are formed upon LMCT excitation of $\left[\mathrm{Hg}\left(\mathrm{N}_{3}\right)_{3}\right]^{-}$under ambient conditions. Mercury atoms in solution are characterized by an intense $\left(\varepsilon \sim 10^{5}\right)$ narrow absorption near $250 \mathrm{~nm}$ which shows band splitting. ${ }^{8,10-12}$ The absorption is assigned to the ${ }^{1} S_{0} \rightarrow{ }^{3} P_{1} s p$ transition of the mercury atoms which are perturbed by the solvent. ${ }^{11,12}$ Due to the low solubility of mercury the photolysis of $\left[\mathrm{Hg}\left(\mathrm{N}_{3}\right)_{3}\right]^{-}$ leads not only to the appearance of atomic mercury but also colloidal mercury.

The photoredox reaction of metal azide complexes induced by LMCT excitation seems to be a rather general method for the generation of free metals which are released as colloids. ${ }^{1}$ It has been suggested that this release is preceded by the generation of free metal atoms which undergo an aggregation to clusters. These clusters grow until they finally reach colloidal dimensions. It is certainly important to identify these intermediate stages under ambient conditions in order to learn more about these processes. The detection of mercury atoms as immediate photolysis product is thus an interesting contribution towards this goal.

The photochemical formation of mercury atoms may also play an important role in the mercuryphotosensitized dehydrodimerization of organic compounds in solution and the gas phase. ${ }^{7,8,18}$ It has been assumed to take place via the formation of some kind of exciplex : ${ }^{18}$

$$
\begin{aligned}
\mathrm{Hg}^{*}+\mathrm{H}-\mathrm{CR}_{3} \rightarrow \mathrm{Hg} * \cdots \mathrm{H}-\mathrm{CR}_{3} & \\
\rightarrow\left[\mathrm{Hg}^{*} \cdots \mathrm{H} \cdots \mathrm{CR}_{3}\right] & \rightarrow \mathrm{Hg}-\mathrm{H}^{*}+{ }^{\cdot} \mathrm{CR}_{3} \\
& \rightarrow \mathrm{Hg}+\mathrm{H}+{ }^{\cdot} \mathrm{CR}_{3} .
\end{aligned}
$$

As an alternative it seems feasible that this reaction proceeds as a photochemical oxidative addition to excited mercury atoms and a subsequent reductive elimination:

$$
\begin{aligned}
\mathrm{Hg}^{*}+\mathrm{H}-\mathrm{CR}_{3} \rightarrow \mathrm{H}-\mathrm{Hg}^{\mathrm{II}}-\mathrm{CR}_{3} & \\
& \rightarrow \mathrm{Hg}^{0}+{ }^{\circ} \mathrm{H}+{ }^{\circ} \mathrm{CR}_{3} .
\end{aligned}
$$

The latter step, which could take place photochemically or thermally, regenerates the mercury atoms. These are now available for a repetition of this process.

\section{REFERENCES}

1. A. Vogler, C. Quett and H. Kunkely, Ber. Bunsenges Phys. Chem. 1988, 92, 1486.

2. W. A. Cramer, J. Phys. Chem. 1967, 71, 1171.

3. V. Balzani and V. Carassiti, Photochemistry of Coordination Compounds. Academic Press, London (1970).

4. A. Vogler and H. Kunkely, J. Organomet. Chem. $1988,355,1$.

5. H. Kunkely, G. Stochel and A. Vogler, Z. Naturfor. 1989, 44b, 145.

6. D. Rehorek and E. G. Janzen, Z. Chem. 1985, 25 , 69.

7. R. R. Kuntz and G. J. Mains, J. Am. Chem. Soc. $1963,85,2219$.

8. J. G. Calvert and J. N. Pitts, Photochemistry. Wiley, New York (1966). 
9. W. Beck, W. P. Fehlhammer, P. Pöllmann, E. Schuierer and K. Feldl, Chem. Ber. 1967, 100, 2335.

10. M. K. Phibbs and B. de B. Darwent, J. Chem. Phys. $1950,18,679$.

11. S. N. Vinogradov and H. E. Gunning, J. Phys. Chem. $1962,68,68$.

12. W. R. Mason, Inorg. Chem. 1988, 27, 437.

13. P. Templet, J. R. McDonald, S. P. McGlynn, C. H. Kendrow, J. L. Roebber and K. Weiss, J. Chem. Phys. 1972, 56, 5746.

14. M. E. Koutek and W. R. Mason, Inorg. Chem. 1980, 19,648 .
15. S. Sakaki, N. Hagiwara, N. Iwasaki and A. Ohyoshi, Bull. Chem. Soc. Jpn 1977, 50, 14.

16. R. A. Walton, R. W. Matthews and C. K. Jørgensen, Inorg. Chim. Acta 1967, 1, 355.

17. P. Day and R. H. Steel, J. Chem. Soc., Dalton Trans. 1972, 2054.

18. S. H. Brown and R. H. Crabtree, J. Am. Chem. Soc. 1989, 111, 2935 and 2946.

19. A. B. P. Lever, Inorganic Electronic Spectroscopy. Elsevier, Amsterdam (1984). 